This is an electronic reprint of the original article. This reprint may differ from the original in pagination and typographic detail.

Author(s): Aittola, Helena

Title: Doctoral education reform in Finland : institutionalized and individualized doctoral studies within European framework

Year: $\quad 2017$

Version:

Please cite the original version:

Aittola, H. (2017). Doctoral education reform in Finland : institutionalized and individualized doctoral studies within European framework. European Journal of Higher Education, 7(3), 309-321. https://doi.org/10.1080/21568235.2017.1290883

All material supplied via JYX is protected by copyright and other intellectual property rights, and duplication or sale of all or part of any of the repository collections is not permitted, except that material may be duplicated by you for your research use or educational purposes in electronic or print form. You must obtain permission for any other use. Electronic or print copies may not be offered, whether for sale or otherwise to anyone who is not an authorised user. 


\section{Doctoral Education Reform in Finland - Institutionalized and Individualized}

Doctoral Studies within European Framework

Helena Aittola

Finnish Institution for Educational research (FIER), University of Jyväskylä, Finland

Helena Aittola, senior researcher, $\mathrm{PhD}$

helena.s.aittola@jyu.fi

Notes on contributors

Helena Aittola is a senior researcher in the Finnish Institute for Educational research, University of Jyväskylä. Her research interests are related to higher education and doctoral education. 


\title{
Doctoral Education Reform in Finland - Institutionalized and Individualized Doctoral Studies within European Framework
}

\begin{abstract}
In Europe, doctoral education systems have been systematically reformed. The reforms are aimed at improving the quality of research and the competitiveness of European countries. In Finland, the reform project of doctoral education started vigorously in the mid-1990s which has contributed significantly to the emergence of more structured doctoral training. The starting point for this article was a recent national follow-up evaluation of doctoral education in Finland. The results are based on qualitative analysis of a survey and interview data collected in the evaluation.
\end{abstract}

The results showed that Finnish universities are launching the university-wide graduate school model. Each university is building a single or several graduate schools consisting of doctoral programmes compatible with the university's research strategies and profiles. Today, there is an apparent need to increase doctoral students' participation in the reform processes. It can be argued that there is discrepancy between the official statements of the doctoral students' key position in promoting research excellence within the European context and the actual doctoral training practices at institutional level. Therefore, we need to explore doctoral students' study conditions from their own perspective, in order to get a better picture of how the new universitywide graduate schools and doctoral programmes promote doctoral graduation in academic, pedagogical and cultural terms.

Key words: higher education; doctoral education; doctoral studies; reform; evaluation 


\section{Introduction}

In Europe, national doctoral education systems have been reformed systematically in recent decades. The reforms are aimed at improving the quality of research and the competitiveness of European countries in the global knowledge economy. Several authors emphasize the necessity of investigating this field (Enders et al. 2011; Faber and Westerheijden 2011; Kehm 2009; Kottman 2011; O'Carroll et al. 2012) as the reforms have far-reaching consequences both nationally and internationally.

Doctoral education has been defined as the third cycle of higher education system since the Berlin Communique 2003, and it plays a central role in the realization of the European Higher Education Area. One of its aims is to promote the comparability of doctoral degrees in Europe and to increase mobility at doctoral and post-doctoral levels (Baschung 2013; Faber and Westerheijden 2011). In order to reach these aims, national higher education systems and agencies need to take international regulations and recommendations into consideration in their doctoral education reforms. Kottman (2011) suggests that the internationalization of higher education policy and the concept of organizational fields explain the dynamics that underlie the dissemination of policies in European doctoral education. The reforms do not proceed straightforwardly, as Saarinen and Välimaa (2012) point out with respect to the Bologna Process. They recognized that transnational influences can find their ways into national policies in different and even surprising ways. Although there is a tendency towards coherence in doctoral education, the objective is not the standardization of doctoral training or harmonization of doctoral degrees, but to retain diversity of doctoral education in Europe (Kottman 2011).

National doctoral education systems vary from country to country according to their higher education traditions and higher education policy conditions. It is somewhat 
misleading to speak about doctoral education universally. Kehm (2009) has found several doctoral education models in Europe. Traditionally, the research doctorate has been focused on a doctoral dissertation aiming to produce an original contribution to the knowledge base of a discipline. Conversely, the taught doctorate consists of course work throughout the degree training and the oral examination. PhD-by-published-work models are characterized by combining several published articles into a book and reviewing them with a coherent framework. In some countries the professional doctorate programme is designed to satisfy the demands of a professional group outside university. Kehm (2009) concludes that this variety makes the comparison and evaluation of different models and programmes challenging, as they serve different purposes and motives. On the whole, the issues of coherence and transparency of doctoral education and the quality of dissertations need further investigation. Therefore, it is also important to take into consideration the specific context of doctoral education reforms and institutional factors of doctoral education practices in each country.

In Finland, the reform project of doctoral education started vigorously in the mid-1990s by establishing the Graduate School system. This reform launched a process of improvements for doctoral education, and it has contributed significantly to the emergence of more structured doctoral training and thereby increased the number of doctoral graduates. The aim of a recent national follow-up evaluation of doctoral education in Finland (Niemi et al. 2011) was to evaluate how the doctoral education system had been developed on the national level, and what kind of structural changes had been made on the university level during the last five years. These main tasks were formally set by the earlier doctoral education evaluation group (Dill et al. 2006), whose evaluation report suggested several amendments for further development of doctoral education. 
The starting point for this article is the new follow-up evaluation report, and a focused analysis of the data collected for the report. The main aim is to examine what kind of changes that Finnish universities have recently launched in doctoral education, and how they have been implemented at institutional level. These changes are examined from the perspective of doctoral students in particular; that is, how they see the ongoing reform process. Even though doctoral education reforms are typically top-down processes, doctoral students should not be treated as passive objects but rather as active participants in the implementation (Planas et al. 2013). Therefore doctoral students' perceptions are considered also as a key factor affecting the success of the whole reform.

In the following, two principal subjects will be examined: first, the doctoral education reform and the changing structures and practices of doctoral training, from the doctoral students' point of view; and second, in order to get a more comprehensive picture, doctoral students' assessments will be examined in the context of interviews with other participants in the follow-up study. In addition, a nation-wide evaluation survey that was conducted before the interviews provides further information on how the ongoing doctoral education reform is perceived at institutional level. In this article the different actors' evaluations on the Finnish doctoral education reform will be discussed thematically in the wider context of research on doctoral education reforms and practices at the European level.

The main research questions of this study are focused on the following themes:

(1) How is the reform of the Finnish doctoral education system perceived at the institutional level?

(2) How do different groups of students and supervisors perceive the quality assurance themes within doctoral education reform (admission procedures, 
doctoral training and doctoral studies, supervision of doctoral studies and dissertations, assessment practices of doctoral dissertations)?

\section{Research Methods}

\section{Study Context and Data}

The follow-up evaluation on doctoral education was carried out by the Finnish Higher Education Evaluation Council (FINHEEC) in 2010-2011. The evaluation comprised two arrays of data collected by a Webropol survey and by interviews with different stakeholder groups from universities. The survey covered all 16 Finnish universities, and selected contact persons from the universities' research and innovation services responded to the survey on behalf of each university. This methodological decision was justified by the fact that the implementation of the new university-wide graduate school model is still underway, and the contact persons were the most suitable to report on this phase of the reform.

In 2011, the total amount of doctoral students studying in Finnish universities was 18125 , of which $17 \%$ were international students. In the same year, the number of doctoral degrees attained was 1653 , and the international students account for $17 \%$ of these degrees. (Vipunen 2016.)

The main themes of the questionnaire focused on the following five areas: introduction of the one-graduate-school model, uniform quality assurance practices in doctoral education, forms of funding in doctoral studies, study situations of part-time and passive doctoral students, and national and international co-operation in doctoral education.

The quality assurance theme in the questionnaire comprised subthemes such as the admission procedures, the supervision of doctoral studies and dissertations, assessment practices of doctoral dissertations, doctoral students' career planning, and 
the work-life relevance of doctoral studies. This study concentrates on these subthemes, because they are the most relevant from the doctoral students' perspective. The survey data provides, in the first instance, factual accounts from the institutional level, but it also gives a mediated view of doctoral students' circumstances as it reveals how the system responds to their needs and expectations in a changing situation.

The objective of the interviews with different groups from universities was to get a focused description of the above mentioned themes. The interviews were conducted with a sample of representatives from six universities. There were participants from the following groups at the group interviews: the rector or vice rector of the university, the professors who were directors of doctoral programmes, and professors who were supervisors of doctoral students, as well as full-time and part-time doctoral students, international supervising professors, international doctoral students, and external stakeholders. Each group had a separate interview session among themselves. In total, there were 61 persons from different university positions participating in 12 interview sessions where fairly identical questions were addressed for different groups. The interview sessions were conducted by the members of the follow-up evaluation group and each of the interviews lasted an hour. The outlines of the interviews were drawn by the secretariat of FINHEEC.

On the whole, the Webropol survey and the interviews with different groups constituted the basic material for the follow-up evaluation report published in Finnish (Niemi et al. 2011). The outlines and extracts from the interviews are not available for this more focused study as such because the original interview material was restricted for the use of the follow-up evaluation study only. Instead, the survey results from 13 universities could be utilized for further research purposes by the universities' 
permission. Thus, these two data sources are viewed as complementary to each other in this article.

The survey consisted of 38 questions. Most of these were open-ended questions focusing on factual knowledge regarding ongoing institutional-level changes in doctoral education. The respondents described the prevailing guidelines and practices quite exactly and referred to official documents or university websites as supplementary material. So, the reliability of the data could be easily confirmed by reviewing official documents. The open-ended answers were analysed thematically by means of content analysis (Creswell 2003; Merriam 2009), looking for the basic institutional decisions. In fact, the universities were in different phases in their doctoral education reforms, and the survey results from the institutional level should be seen against this framework.

The qualitative interview data published in Finnish (Niemi et al. 2011, Tohtorikoulutuksen rakenteet muutoksessa. Tohtorikoulutuksen kansallinen seurantaarviointi) and used as evidence of doctoral students' and supervisors' perceptions of the reform process. The basic aim for more focused analysis of the data was to provide qualitative descriptions of the quality assurance themes from their point of view.

\section{Findings}

\section{Doctoral Education Reform in Finland and Doctoral Students' Role in Designing the}

\section{Reform Process}

The first objective of the Finnish follow-up evaluation study was also to explore how universities have made progress in reforming the basic structures of their doctoral education. According to the survey answers, Finnish universities introduced a university-wide graduate school model for doctoral training during 2011. The aim of this structural reform was considered to consolidate universities' own responsibility for 
doctoral education, and to make doctoral education a more integral part of their research activities.

According to the survey, each Finnish university was building a single or several graduate schools offering of doctoral programmes compatible with the university's research strategies and profiles. It can be argued that the basic principles of the reform and the model for graduate schools were partly 'predetermined' as the common principles of operation meant to follow national recommendations, and to match other universities' doctoral education systems. This notion was stated explicitly in the following survey response: "The operation model of the university-wide graduate school was expected to take into account the national development policies for doctoral education and also co-operation with other universities."

The follow-up survey revealed that even though doctoral students have a significant impact on academic research, they still have but a minor role in academic decision-making processes concerning doctoral education. Only one university reported that they had a doctoral students' representative in the Board of doctoral education at the university level. Hence, universities have not actually pursued the recommendation of the earlier evaluation report (Dill et al. 2006) that called for doctoral students' active participation in the implementation of doctoral education reform. The survey results indicate that the basic structural changes were centrally designed and launched by a topdown manner in the universities.

\section{The Changing Structures and Practices of Doctoral Training}

In order to make doctoral training more systematic and transparent, Finnish universities are setting up new guidelines for the different phases of the whole doctoral education programme: for admission, training, and supervision, as well as for monitoring and 
assessing of study processes and dissertations. In the first instance, these procedures are intended to meet doctoral students' needs for systematically organized doctoral studies.

\section{Admission Process to Doctoral Education Becoming more Transparent}

The previous evaluation report of Finnish doctoral education (Dill et al. 2006) identified many shortcomings in the selection process of candidates admitted to doctoral studies. The survey indicated that since then, the universities have made their admission criteria to doctoral studies more accessible via their websites, and the information is available in most universities not only in Finnish but also in English. Therefore, it is now easier also for foreign students to get detailed information about doctoral studies in Finland.

An obligatory requirement for doctoral studies is a relevant Master's degree as stipulated in the Universities Act 558/2009, and the grade of the Master's thesis gives an indication of the candidate's capacity to succeed in doctoral studies. The survey showed that universities are applying a comprehensive set of criteria to their selection process. The most common selection criteria include the prior approval of the doctoral candidate's research topic, which should be applicable to the research field of the aimed doctoral programme. This procedure will most likely guarantee there is appropriate supervision and funding for doctoral studies, as the following survey response shows: "When selecting new doctoral students, faculties consider now more carefully whether there is appropriately high-quality supervision and support available for the particular research topic." Secondly, the doctoral candidate has to provide a tentative research plan as well as a study plan so as to outline the realization of doctoral studies. These plans should be drafted in collaboration with the prospective supervisor. Thirdly, the nomination process of the main supervisor and other supervisors must be accomplished 
before the enrolment. These criteria are applied almost uniformly at each Finnish university.

In recent years, a clearly stated objective in Finnish higher education policy has been to intensify the recruitment of international doctoral candidates according to European recommendations. The aim is that $20 \%$ of the $\mathrm{Ph} . \mathrm{D}$. degrees should be awarded to international doctoral students (Treuthardt and Nuutinen 2012). The survey revealed that the number of international doctoral students varies greatly between institutions and disciplines. The supervisors interviewed explained that the selection process for international doctoral candidates is not self-evident, as the amount and quality of international doctoral candidates' applications varies from year to year.

\section{Comprehensive Array of Doctoral Training}

The survey shed light on the different ways in which universities implement new institutional structures and practices in doctoral training. Previously, faculties, departments or individual doctoral programmes provided courses in their specific fields, but now, according to the survey responses, the aim is that the university's graduate school would take more responsibility for organizing common courses including scientific research methods, communication skills, career planning, ethical issues, and good scientific practices for all doctoral students.

The interviewed groups in the follow-up evaluation saw that communication skills, project management, knowhow in grant application, teamwork, and networking internationally will promote careers in academia as well as in other sectors. Although the provision of doctoral training has become more comprehensive, the international students interviewed complained about the scarcity of courses taught in English. The directors and supervisors interviewed admitted that universities should be better 
prepared to provide tuition in English to serve the needs of a growing number of international doctoral students.

All the interviewed groups of supervisors and doctoral students emphasized the relevance of different kind of courses, but considering the total duration of doctoral studies, they assumed that it could be difficult to fit a large variety of courses and coursework into individual doctoral study plans. After all, doctoral students' main task is to pursue their own research and prepare their doctoral dissertations within certain time limits.

It is possible, however, to take doctoral students' different backgrounds into consideration and design their individual study plans and coursework to respond to their career prospects. The groups interviewed affirmed that research work in itself provides various applicable qualifications for working outside academia. The supervisors interviewed stated that most of the universities were also launching optional workinglife and business skills courses for doctoral students, to broaden the students' career perspectives.

Both the survey and interview data indicated that national and international cooperation between doctoral programmes, especially in organizing seminars and conferences, has become more common in recent years. These have enhanced the exchange of experiences and contributed to a certain degree of convergence in doctoral training between national and international programmes.

The respondents to the survey and interviews were looking forward to a time when the university-wide graduate school model will encompass all doctoral education. These changes will ensure that the supply of doctoral training will more fully meet the needs of different doctoral student groups with regard to their discipline, research work, and heterogeneous status as doctoral students. 
Supervision of doctoral studies and dissertation should be at the core of doctoral education. There is a huge body of academic studies and guidebooks concerning various aspects of doctoral supervision to confirm its primary role from the students' point of view. Supervision is also seen as the most important component contributing to graduation (e.g. Deuchar 2008; Halse and Malfroy 2010; Lee 2008; Sambrook, Stewart, and Roberts 2008; Vilkinas 2008; Wisker 2005).

As compared to the findings of the previous evaluation of Finnish doctoral education (Dill et al. 2006), the follow-up evaluation confirmed that supervision has become more systematically organized at institutional level. The survey data showed that universities set clearly defined tasks and responsibilities for the implementation of supervision at different levels, in order to ensure its high quality. The survey revealed that contracts between supervisors and doctoral students to define their obligations and responsibilities have been implemented gradually. In fact, the contract is not a legally binding document, but more like an agreement of responsibilities. The supervisors and doctoral students interviewed welcomed the contracts in principle but they had also some reservations because formal agreements might add bureaucracy, and strict regulations are not appropriate for the supervision relationship in practice.

Although the individualized supervision relationship has a recognized status in doctoral studies, all interviewed groups agreed with the idea that supervision responsibilities should be shared more widely. The survey data indicated that in doctoral programmes, follow-up groups are nominated to monitor the students' progress. From the quality assurance perspective, an important additional role for these groups is to gather feedback from doctoral students about the quality of supervision relationships. In meetings with the follow-up group, doctoral students can also take up any harmful 
disagreements between a supervisor and a doctoral student that might threaten smooth progress in their doctoral studies. The next extract illustrates this possibility: "The monitoring groups discuss about individual supervisors' work and seek to inform them about the feedback received."

The doctoral students interviewed reported that students are not necessarily aware of the institutional codes of conduct for supervision. They do not know how to proceed in conflict situations as the relationship between a single supervisor and a student is usually so personal. The interviewed supervisors admitted that there is an obvious need to provide more information and institutional guidelines for conflict situations to prevent confusion and to ensure equal conduct. In sum, the doctoral students interviewed highlighted that the prevailing feedback systems in supervision are not working adequately, from their point of view.

Even though the survey results suggested that new guidelines for supervision may unify supervisory practices at institutional level, the interviewed supervisors and doctoral students pointed out that the supervision of research is mainly based on the traditions of the discipline. The nature of scientific work and established ways of pursuing research in different fields of research contribute to supervision relationships. The respondents assumed that the new organization of doctoral studies is likely to give rise to a new institutionally legitimized supervision culture and practices.

The doctoral students interviewed envisaged that the supervisory tasks could be assigned to a larger group in the research community. In particular, discussions and feedback from other doctoral students in research seminars can considerably advance the research process. Doctoral students also found social and emotional support from peers extremely valuable in various study situations. According to the interviews with doctoral students, supervisors have a central role in introducing doctoral students to 
international scholars in conferences so that the students can discuss their studies, get feedback, and establish valuable research networks as junior researchers. Part-time doctoral students interviewed found their position as more unfavourable, because their contacts with their supervisors and peers were rather infrequent, and they had no extra funding for conferences. Current supervision practices were not responding adequately to their particular supervision needs. The survey responses affirmed that it will be a great challenge to the new university-wide graduate school system and doctoral programmes to provide research funding and social support equally for part-time doctoral student groups.

\section{Unified Assessment Processes of Doctoral Dissertations}

The quality of doctoral dissertations is a widely discussed topic in international contexts (Bourke and Holbrook 2013; EUA 2005, 2010; Kyvik 2014; Lovat et al. 2015). In Finland, the quality issues have been on the doctoral education agenda since the outset of the system reform (see e.g. Aittola 2001, 2008). In fact, a peer review system is the main procedure to assess the quality of dissertations, while follow-up evaluation studies can only investigate how the assessment processes have been assigned at institutional level. The previous evaluation of doctoral education (Dill et al. 2006) found many weaknesses in the Finnish assessment system of doctoral dissertations. These concerned mainly the undefined roles of different actors, and their tasks in the assessment process. In addition, the quality of doctoral dissertations seemed not to be monitored systematically at the institutional and national level.

According to the information from the recent survey, Finnish universities have adopted comprehensive quality assurance procedures for the assessment of dissertations, since the universities have taken more responsibility for their doctoral 
education. Now, universities provide explicit information of the evaluation process of dissertations on their websites, including specific tasks and timetables for different actors. From the doctoral students' viewpoint, it is even more important that they can find detailed information on the assessment criteria of doctoral dissertations in their faculty's study guide, and that relevant information about assessment is shared throughout their doctoral studies. Furthermore, the survey showed that in order to harmonize the assessment process across the reviewers, the procedures and criteria of assessment are given in writing to reviewers and opponents upon their nomination. As a rule, many institutions and faculties provide their assessment guidelines also in English, owing to the rising number of opponents from abroad.

There are also some other factors contributing to the changes in assessment processes in the context of Finnish doctoral education. In some disciplines, a majority of the dissertations are composed of published articles that have been checked and approved by international reviewers. Although the article compilation thesis format is surpassing the traditional monograph mode in some fields, there are still many open questions according to the follow-up evaluation data as regards the number of submitted articles, the level of the target journal etc. The interviewed supervisors argued that there is an urgent need for nation-wide negotiations on these fundamental requirements to ensure uniform standards for dissertations. The doctoral students interviewed also complained that the requirements for doctoral dissertation and related assessment criteria as to article compilation for theses may even vary between different units within the same discipline. 


\section{Conclusions}

It is reasonable to examine the findings of this study in the context of European doctoral education reforms in order to obtain a better understanding of the ongoing changes. Kottman (2011) argues that in the European context, doctoral education reforms have moved from the national level to the European level. The current Finnish doctoral education reform also follows the basic guidelines of the Salzburg principles (EUA 2005, 2010), as the doctoral education system is becoming more coherent and systematized nationally and at the institutional level. On the other hand, Kehm (2009) argues that with the individualized approach, the responsibility of the individual department and supervisor for the reform of doctoral education has been shifted to the institutional level.

In the European context, topics concerning doctoral education have been widely discussed within the Bologna Process third cycle and quality assurance framework. The trend has been towards more structured and internationally comparable doctoral education systems and programmes all over European countries. There have been written regulations assigned, along with guidelines for steering doctoral education reforms at national and institutional level, to provide more transparent and efficient doctoral education systems and practices. At the international and supranational level, principles like competiveness, comparability, employability and mobility have been put at the forefront of the agenda. Correspondingly, most of the guidelines at institutional level deal with more concrete questions, such as admission procedures, learning outcomes, supervision practices, and the assessment of doctoral dissertations. In short, the aim is to provide doctoral education within more properly defined and structured doctoral education programmes, both to improve the quality of doctoral education and 
to strengthen research capacity in Europe. (Brox and Kuhn 2012; Byrne, Jørgensen, and Loukkola 2013; Repečkaitė 2016).

The university-wide model of graduate schools in Finland integrates research and doctoral education more tightly with the universities' strategies and research profiles. Thus, each university is expected to differentiate itself from the other universities, and to attract the most prominent researchers and doctoral candidates to their specific fields of research and doctoral programmes (Ministry of Education and Culture 2012).

In the context of European recommendations for doctoral education, the Finnish doctoral education reform and the new organizational structure, the university-wide graduate school, is being constructed in such a way as to enhance universities' responsibilities in doctoral education. The survey indicated that Finnish universities are organizing university-wide graduate schools that harmonize with the unique nature and size of each university. Thus, the structural solutions chosen in each university respond to the challenge of reorganizing doctoral education according to national and European guidelines as well. A basic question in doctoral education policy is how the principle of diversity is tolerated, or even encouraged, at system and institutional level (Enders et al. 2011).

The Finnish doctoral education system has not changed substantially as regards to the number of doctoral students or the number of attained doctoral degrees in recent years. According to the recommendations (Ministry of Education and Culture 2016), the total degree target of 1600 doctoral degrees will not be raised in the near future. There were 18174 doctoral students studying in Finnish universities in 2015, and the proportion of international students has risen slightly, to $20 \%$. One of the main targets of the Finnish doctoral education reform is to attract more international students to 
Finnish doctoral education programmes. During the implementation period of university-wide graduate schools from 2011 to 2015, the proportion of attained doctoral degrees among international doctoral students has risen from $17 \%$ to $21 \%$. (Vipunen 2016.) Therefore, the recommendation for awarding $20 \%$ of the $\mathrm{PhD}$ degrees to international doctoral students (Treuthardt and Nuutinen 2012) has been achieved. This may demonstrate how the Finnish doctoral education system has become more transparent and internationally comparable for international doctoral students, and that it has responded to their educational needs quite successfully.

One of the main aims of this paper was to examine the prevailing transition phase from the doctoral students' point of view. The data indicated that their understanding of the ongoing process is rather limited, as the implementation of the reform has been carried out in a top-down manner (Brox and Kuhn 2012). On the whole, it can be argued that due to the latest Finnish doctoral education reform the basic structures and processes in doctoral training will become more student-centred (François, Lefort, and White 2012). At institutional level, most of the revised guidelines and practices are aimed at supporting doctoral students' study processes. The institutional procedures tell how to apply for doctoral studies and how to proceed in planning and pursuing doctoral studies after enrolment. The university-wide graduate schools presuppose that supervisors, supervisory or follow-up groups will monitor the doctoral candidate's individual study progress to ensure graduation within four years of full-time studies. In particular, if the progress is not satisfactory and the funding for the whole programme is inadequate, the graduate school can apply procedural sanctions in order to encourage graduation. In this regard, the responsibilities of supervisors and follow-up groups will not be shifted to the institutional level. 
There are some undeniable advantages connected with the institutionalized model of doctoral education. Institutional structures provide a firm and supportive framework for doctoral studies. Departments are obliged to provide uniform and transparent guidelines for basic process in doctoral education, that is, for admission, supervision and assessment processes. The institutions are also more concerned about prolonged doctoral studies and the rate of drop-outs, and try to enhance doctoral students' study conditions at institutional level. For this reason, institutions are also strengthening the work-life relevance of doctoral studies by launching working life oriented courses and creating contacts with different employees to improve doctoral students' career opportunities outside academia (Auriol, Misu, and Freeman 2013). In a wider European context, the transparency of doctoral education will promote both research collaboration and the mobility of researchers. The most obvious disadvantages connected to institutionalized model of doctoral education are connected to its formality. It disregards discipline-based traditions and practices, and supervision practices will become overly formalized. (Brox and Kuhn 2012; Phelan 2013.)

The advantages of individualized model of doctoral studies are connected to its responsiveness to discipline specific, local and situational factors (e.g. Baker and Pifer 2015). It encourages more whole-hearted relationships between supervisors and doctoral candidates and negotiations about students' individual study conditions and personal matters during doctoral studies. The individualized model's disadvantages are connected to its incapacity to perceive the wider context of doctoral education, and seem to be unconcerned about accountability issues and time limits for doctoral graduation. Doctoral students may become too reliant on their supervisors, and equal conduct of all doctoral students will be endangered. 
Today, according to the follow-up study, there is an apparent need to increase doctoral students' participation in the processes of the Finnish doctoral education reform and get their voices heard appropriately. After all, they are at the core of doctoral education, while the institutions are to provide them with favourable conditions and facilitate doctoral education, including relevant training and supervision of high quality (Planas et al. 2013). It can be argued that there is some discrepancy between the official statements of the doctoral students' key position in promoting and sustaining research excellence within the European context, and the actual doctoral training practices at the institutional level. Therefore, we need to explore doctoral students' study conditions and experiences from their own perspective more systematically, in order to obtain a better picture of how the new university-wide graduate schools and doctoral programmes promote doctoral graduation in academic, pedagogical, and cultural terms (Halse and Mowbray 2011). In this respect, investigation on the implementation of the Finnish doctoral education reform is still in its early stages.

\section{References}

Aittola, H. 2001. "Academic Life and the Pressure of Massification." In Finnish Higher Education in Transition: Perspectives on Massification and Globalisation, edited by J. Välimaa, 111-138. Jyväskylä: University of Jyväskylä. Institute for Educational Research.

Aittola, H. 2008. "Doctoral Education and Doctoral Theses - Changing Assessment Practices.” In Cultural Perspectives on Higher Education, edited by J. Välimaa and O.-H. Ylijoki, 161-177. Dordrecht: Springer.

Auriol, L., M. Misu, and R. A. Freeman. 2013. "Careers of Doctorate Holders: Analysis of Labour Market and Mobility Indicators.” OECD Science, Technology and 
Industry Working Papers, 2013/04. Paris: OECD.

http://dx.doi.org/10.1787/5k43nxgs289w-en.

Baker, V. L., and M. J. Pifer. 2015. "Antecedents and Outcomes: Theories of Fit and the Study of Doctoral Education." Studies in Higher Education 40 (2): 296-310.

Baschung, L. 2013. Doctoral Education's Reform in Switzerland and Norway: A Public Management Analysis. New York: Peter Lang.

Bourke, S., and A. P. Holbrook. 2013. "Examining PhD and Research Masters Theses." Assessment \& Evaluation in Higher Education 38 (4): 407-416.

Brox, C., and W. Kuhn. 2012. "Structured or Non-Structured Doctoral Programmes? A Bottom-up Approach for Third-Cycle Bologna Implementation. "Paper presented at the annual meeting for the Society of the 8th European GIS education seminar, Leuven, September, 6-9.

Byrne, J., T. Jørgensen, and T. Loukkola. 2013. Quality Assurance in Doctoral Education - Results of the ARDE Project. EUA: Brussels EUA.

Creswell, J. W. 2003. Research Design: Qualitative, Quantitative, and Mixed Methods Approaches. Thousand Oaks: Sage.

Deuchar, R. 2008. "Facilitator, Director or Critical Friend?: Contradiction and Congruence in Doctoral Supervision Styles." Teaching in Higher Education 13 (4): $489-500$.

Dill, D. D., S. K. Mitra, H. S. Jensen, E. Lehtinen, T. Mäkelä, A. Parpala, H. Pohjola, M. A. Ritter, and S. Saari. 2006. PhD Training and the Knowledge-based Society: An Evaluation of Doctoral Education in Finland. Publications of the Finnish Higher Education Evaluation Council 1:2006. Helsinki: Finnish Higher Education Evaluation Council. 
Enders, J., H. F.de Boer, J. File, B. Jongbloed, and D. F. Westerheijden. 2011. "Reform of Higher Education in Europe." In Reform of Higher Education in Europe, edited by J. Enders, H. F. de Boer, and D. F. Westerheijden, 1-10. Rotterdam: Sense Publishers.

EUA. European University Association. 2005. Doctoral programmes for the European Knowledge Society: Report on the EUA Doctoral Programmes Project 2001-2005. Brussels: EUA.

EUA. European University Association. 2010. Salzburg II Recommendations: European universities' Achievements since 2005 in Implementing the Salzburg Principles. EUA: Brussels.

Faber, M., and D. F. Westerheijden. 2011. "European Degree Structure and National Reform: Constitutive Dynamics of the Bologna Process." In Reform of Higher Education in Europe, edited by J. Enders, H. F. de Boer, and D. F. Westerheijden, 11-28. Rotterdam: Sense Publishers.

François, A., M. Lefort, and D. White. 2012. “Doctoral Candidates: Individual Accompaniment to Promote Development of Skills for a Successful Professional Career." Journal of the European Higher Education Area (3): 59-82. http://www.eheajournal.eu/index.php?option=com_docman\&task=doc_details\&gid=335.

Halse, C., and J. Malfroy. 2010. "Retheorizing Doctoral Supervision as Professional Work." Studies in Higher Education 35 (1): 79-92.

Halse, C., and S. Mowbray. 2011. "The Impact of the Doctorate." Studies in Higher Education 36 (5): 513-525. 
Kehm, B. M. 2009. “Doctoral Education- Quo Vadis?” In The Research Mission of the University: Policy Reforms and Institutional Response, edited by P. Clancy and D.D. Dill, 197-211. Rotterdam: Sense Publishers.

Kottman, A. 2011. "Reform of Doctoral Training in Europe: A Silent Revolution?. "In Reform of Higher Education in Europe, edited by J. Enders, H. F. de Boer, and D. F. Westerheijden, 29-43. Rotterdam: Sense Publishers.

Kyvik, S. 2014. “Assessment Procedures of Norwegian PhD Theses as Viewed by Examiners from the USA, the UK and Sweden." Assessment \& Evaluation in Higher Education 39 (2): 140-153.

Lee, A. 2008. "How are Doctoral Students Supervised? Concepts of Doctoral Research Supervision.” Studies in Higher Education 33 (3): 267-281.

Lovat, T., A. Holbrook, S. Bourke, H. Fairbairn, M. Kiley, B. Paltridge, and S. Starfield. 2015. "Examining doctoral examination and the question of the Viva." Higher Education Review 47 (3): 5-23.

Merriam, S. B. 2009. Qualitative Research: A Guide to Design and Implementation. San Francisco: Jossey-Bass.

Ministry of Education and Culture. 2012. Education and Research 2011-2016: A Development Plan. Reports of the Ministry of Education and Culture, Finland 2012:3. Helsinki: Ministry of Education and Culture. http://www.minedu.fi/export/sites/default/OPM/Julkaisut/2012/liitteet/okm03.pdf. Ministry of Education and Culture. 2016. Tutkijanuran tilannekuva:

Tutkijanuratyöryhmän loppuraportti. [The situational picture of research careers. The final report of the working group for research careers.; in Finnish, Description in English]. Publications of the Ministry of Education and Culture, Finland 2016:2. Helsinki: Ministry of Education and Culture. 
http://www.minedu.fi/OPM/Julkaisut/2016/tutkijanura.html?lang=fi\&extra_locale=e n.

Niemi, H., H. Aittola, V. Harmaakorpi, O. Lassila, S. Svärd, J. Ylikarjula, K. Hiltunen, and K. Talvinen. 2011. Tohtorikoulutuksen rakenteet muutoksessa:

Tohtorikoulutuksen kansallinen seuranta-arviointi. [PhD Training in Transition - A National Follow-up Evaluation of Doctoral Education in Finland; in Finnish]. The Finnish Higher Education Evaluation Council FINHEEC Publications 15:2011, Abstract in English. Helsinki: Finnish Higher Education Evaluation Council FINHEEC.

O’Carroll, C., L. Purser, M. Wislocka, S. Lucey, and N. McGuinness, N. 2012. “The $\mathrm{PhD}$ in Europe: Developing a System of Doctoral Training that will Increase the Internationalisation of Universities." In European Higher Education at the Crossroads: Between the Bologna Process and National Reforms, edited by A. Curaj, P. Scott, L. Vlasceanu, and L. Wilson, 461-484. Dordrecht: Springer.

Phelan, D. R. 2013. “The pros and cons of interdisciplinary structured PhDs in European studies." European Journal of Higher Education 3 (4): 402-405. doi:10.1080/21568235.2013.825073.

Planas, A., P. Soler, J. Fullana, M. Pallisera, and M. Vilà. 2013. Student Participation in University Governance: The Opinions of Professors and Students. Studies in Higher Education 38 (4): 571-583.

Repečkaitè, D. 2016. "Reframing European doctoral training for the new ERA." European Journal of Higher Education 6 (3): 256-270. doi:10.1080/21568235.2015.1126792.

Saarinen, T., and J. Välimaa. 2012. "Changes as an Intellectual Device and as an Object of Research." In Managing Reforms in Universities: The Dynamics of Culture, 
Identity and Organizational change, edited by B. Stensaker, J. Välimaa, and C. Sarrico, 41-60. Basingstoke: Palgrave Macmillan.

Sambrook, S., J. Stewart, and C. Roberts. 2008. "Doctoral Supervision ... a View from Above, Below and the Middle!" Journal of Further and Higher Education 32 (1): $71-84$.

Treuthardt, L., and A. Nuutinen. 2012. The State of Scientific Research in Finland 2012. Publications of the Academy of Finland 7/12. Helsinki: Academy of Finland. Universities Act 558/2009. http://www.finlex.fi/en/laki/kaannokset/2009/en20090558.pdf.

Vilkinas, T. 2008. “An Exploratory Study of the Supervision of Ph.D./Research Students’ Theses." Innovative Higher Education 32 (5): 297-311.

Vipunen. Education Statistics Finland. 2016. University education. https://vipunen.fi/en-gb/university-education.

Wisker, G. 2005. The Good Supervisor: Supervising Postgraduate and Undergraduate Research for Doctoral Theses and Dissertations. Basingstoke: Palgrave Macmillan. 